Pacific Journal of Mathematics

SOME TRIPLE INTEGRAL EQUATIONS 


\section{SOME TRIPLE INTEGRAL EQUATIONS}

\section{JoHN S. LOWNDES}

In this paper we solve the triple integral equations

(1) $\mathfrak{M}^{-1}\left\{\frac{\Gamma(\xi+s / \delta)}{\Gamma(\xi+\beta+s / \delta)} \Phi(s) ; x\right\}=0,0 \leqq x<a, b<x<\infty$,

$$
\mathfrak{M}^{-1}\left\{\frac{\Gamma(1+\eta-s / \sigma)}{\Gamma(1+\eta+\alpha-s / \sigma)} \Phi(s) ; x\right\}=f_{2}(x), a<x<b,
$$

where $\alpha, \beta, \xi, \eta, \delta>0, \sigma>0$, are real parameters, $f_{2}(x)$ is a known function, $\Phi(s)$ is to be determined and

$$
\mathfrak{M}\{h(x) ; s\}=H(s), \mathfrak{M}^{-1}\{H(s) ; x\}=h(x),
$$

denote the Mellin transform of $h(x)$ and its inversion formula respectively.

The above equations are an extension of the dual integral equations solved in a recent paper by Erdélyi [2] by means of a systematic application of the Erdélyi-Kober operators of fractional integration [4].

Using the properties of some slightly extended forms of the Erdélyi-Kober operators we show, in a purely formal manner, that the solution of the triple integral equations can be expressed in terms of the solution of a Fredholm integral equation of the second kind. Srivastav and Parihar [5] have solved a very special case of the equations by a completely different method from that used in this paper. The method of solution employed here will be seen to follow closely that used by Cooke [1] to obtain the solution to some triple integral equations involving Bessel functions; indeed Cooke's equations may be regarded as a special case of equations (1) and (2) and it is shown that a solution of his equations can be readily obtained from that presented in this paper.

2. The integral operators. We shall use the integral operators defined by

$$
\begin{aligned}
I_{\eta, \alpha}(\alpha, x: \sigma) f(x) & =\frac{\sigma x^{-\sigma(\alpha+\eta)}}{\Gamma(\alpha)} \int_{a}^{x}\left(x^{\sigma}-t^{\sigma}\right)^{\alpha-1} t^{\sigma(\eta+1)-1} f(t) d t, \quad \alpha>0, \\
& =\frac{x^{1-\sigma(\alpha+\eta+1)}}{\Gamma(1+\alpha)} \frac{d}{d x} \int_{a}^{x}\left(x^{\sigma}-t^{\sigma}\right)^{\alpha} t^{\sigma(\gamma+1)-1} f(t) d t, \\
& -1<\alpha<0,
\end{aligned}
$$

$$
K_{\eta, \alpha}(x, b: \sigma) f(x)=\frac{\sigma x^{\sigma \eta}}{\Gamma(\alpha)} \int_{x}^{b}\left(t^{\sigma}-x^{\sigma}\right)^{\alpha-1} t^{\sigma(1-\alpha-\eta)-1} f(t) d t, \quad \alpha>0,
$$




$$
\begin{array}{r}
=-\frac{x^{\sigma(\eta-1)+1}}{\Gamma(1+\alpha)} \frac{d}{d x} \int_{x}^{b}\left(t^{\sigma}-x^{\sigma}\right)^{\alpha} t^{\sigma(1-\alpha-\eta)-1} f(t) d t, \\
-1<\alpha<0,
\end{array}
$$

where $a<x<b, \sigma>0$.

When $a=0, b=\infty$, these become the extended form of the Erdélyi-Kober operators used in [2] and when $\sigma=2$ they are the same as the operators defined by Cooke [1].

From the theory of Abel integral equations it follows that the inverse operators are given by

$$
\begin{aligned}
I_{\eta, \alpha}^{-1}(a, x: \sigma) f(x) & =I_{\eta+\alpha,-\alpha}(a, x: \sigma) f(x), \\
K_{\eta, \alpha}^{-1}(x, b: \sigma) f(x) & =K_{\eta+\alpha,-\alpha}(x, b: \sigma) f(x) .
\end{aligned}
$$

We shall also find it convenient to have expressions for integral operators of the type

$$
\begin{aligned}
& L_{\eta, \alpha}(0, x: \sigma) f(x)=I_{\eta, \alpha}^{-1}(a, x: \sigma) I_{\eta, \alpha}(0, \alpha: \sigma) f(x), \quad 0<a<x, \\
& M_{\eta, \alpha}(x, b: \sigma) f(x)=K_{\eta, \alpha}^{-1}(x, a: \sigma) K_{\eta, \alpha}(a, b: \sigma) f(x), \quad x<a<b .
\end{aligned}
$$

When $0<\alpha<1$, we see on using the results (4), (5) and (8) that

$$
\begin{aligned}
L_{\eta, \alpha}(0, x: \sigma) f(x)=\frac{\sigma x^{1-\sigma(\eta+1)}}{\Gamma(\alpha) \Gamma(1-\alpha)} \frac{d}{d x} & \int_{a}^{x}\left(x^{\sigma}-t^{\sigma}\right)^{-\alpha} t^{\sigma-1} d t \\
& \int_{0}^{a}\left(t^{\sigma}-u^{\sigma}\right)^{\alpha-1} u^{\sigma(\eta+1)-1} f(u) d u .
\end{aligned}
$$

Inverting the order of integration and using the result

$$
\begin{aligned}
\frac{d}{d x} \int_{a}^{x} \frac{t^{\sigma-1} d t}{\left(x^{\sigma}-t^{\sigma}\right)^{\alpha}\left(t^{\sigma}-u^{\sigma}\right)^{1-\alpha}}=\frac{x^{\sigma-1}\left(a^{\sigma}-u^{\sigma}\right)^{\alpha}}{\left(x^{\sigma}-u^{\sigma}\right)\left(x^{\sigma}-a^{\sigma}\right)^{\alpha}}, \\
u<a<x, 0<\alpha<1,
\end{aligned}
$$

we find

$$
\begin{aligned}
L_{\eta, \alpha}(0, x: \sigma) f(x)= & \frac{\sigma \sin (\alpha \pi)}{\pi} \frac{x^{-\sigma \eta}}{\left(x^{\sigma}-a^{\sigma}\right)^{\alpha}} \\
& \int_{0}^{a} \frac{u^{\sigma(\eta+1)-1}\left(a^{\sigma}-u^{\sigma}\right)^{\alpha}}{x^{\sigma}-u^{\sigma}} f(u) d u .
\end{aligned}
$$

Similarly we can show that

$$
\begin{aligned}
M_{\eta, \alpha}(x, b: \sigma) f(x)= & \frac{\sigma \sin (\alpha \pi)}{\pi} \frac{x^{\sigma(\alpha+\eta)}}{\left(a^{\sigma}-x^{\sigma}\right)^{\alpha}} \\
& \int_{a}^{b} \frac{u^{\sigma(1-\alpha-\eta)-1}\left(u^{\sigma}-a^{\sigma}\right)^{\alpha}}{u^{\sigma}-x^{\sigma}} f(u) d u,
\end{aligned}
$$

where $0<\alpha<1$. 
When $-1<\alpha<0$, the formulae for $L_{\eta, \alpha}$ and $M_{\eta, \alpha}$ are exactly the same as those given by the above equations.

We also have the expressions

$$
\begin{aligned}
& I_{\eta+\alpha,-\alpha}(0, a: \sigma) I_{\eta, \alpha}(0, x: \sigma) f(x) \\
& \quad=\left[I_{\eta, \alpha}^{-1}(0, x: \sigma)-I_{\eta, \alpha}^{-1}(a, x: \sigma)\right] I_{\eta, \alpha}(0, x: \sigma) f(x) \\
& \quad=f(x)-I_{\eta, \alpha}^{-1}(a, x: \sigma)\left[I_{\eta, \alpha}(0, a: \sigma)+I_{\eta, \alpha}(a, x: \sigma)\right] f(x) \\
& \quad=-I_{\eta, \alpha}^{-1}(a, x: \sigma) I_{\eta, \alpha}(0, a: \sigma) f(x)=-L_{\eta, \alpha}(0, x: \sigma) f(x), \\
& \quad K_{\eta+\alpha,-\alpha}(a, b: \sigma) K_{\eta, \alpha}(x, b: \sigma) f(x)=-M_{\eta, \alpha}(x, b: \sigma) f(x) .
\end{aligned}
$$

Two well known results [2] which play an important part in our solution are

$$
\begin{gathered}
\mathfrak{M}\left(I_{\eta, \alpha}(0, x: \sigma) f(x) ; s\right\}=\frac{\Gamma(1+\eta-s / \sigma)}{\Gamma(1+\eta+\alpha-s / \sigma)} \mathfrak{M}\{f(x) ; s\}, \\
\mathfrak{M}\left\{K_{\eta, \alpha}(x, \infty: \sigma) f(x) ; s\right\}=\frac{\Gamma(\eta+s / \sigma)}{\Gamma(\eta+\alpha+s / \sigma)} \mathfrak{M}\{f(x) ; s\}
\end{gathered}
$$

In what follows we are concerned with three ranges of the variable $x$, namely

$$
I_{1}=\{x: 0 \leqq x<a\}, I_{2}=\{x: a<x<b\}, I_{3}=\{x: b<x<\infty\},
$$

and we shall write any function $f(x), x \geqq 0$, in the form

$$
f(x)=\sum_{i=1}^{3} f_{i}(x)
$$

where

$$
f_{i}(x)=\left\{\begin{array}{l}
f(x), x \in I_{i}, \\
0, \text { otherwise },
\end{array} \quad i=1,2,3 .\right.
$$

With these definitions it is easily seen that if we evaluate the equations

$$
g(x)=I_{\eta, \alpha}(0, x: \sigma) f(x), h(x)=K_{\eta, \alpha}(x, \infty: \sigma) f(x),
$$

on the intervals $I_{1}, I_{2}$ and $I_{3}$ respectively, we get

$$
\begin{aligned}
g_{1}(x)= & I_{\eta, \alpha}(0, x: \sigma) f_{1}(x), \\
h_{1}(x)= & K_{\eta, \alpha}(x, a: \sigma) f_{1}(x)+K_{\eta, \alpha}(a, b: \sigma) f_{2}(x)+K_{\eta, \alpha}(b, \infty: \sigma) f_{3}(x), \\
& g_{2}(x)=I_{\eta, \alpha}(0, a: \sigma) f_{1}(x)+I_{\eta, \alpha}(a, x: \sigma) f_{2}(x), \\
& h_{2}(x)=K_{\eta, \alpha}(x, b: \sigma) f_{2}(x)+K_{\eta, \alpha}(b, \infty: \sigma) f_{3}(x), \\
g_{3}(x)= & I_{\eta \alpha}(0, a: \sigma) f_{1}(x)+I_{\eta \alpha}(a, b: \sigma) f_{2}(x)+I_{\eta \alpha}(b, x: \sigma) f_{3}(x), \\
h_{3}(x)= & K_{\eta, \alpha}(x, \infty: \sigma) f_{3}(x) .
\end{aligned}
$$


3. Solution of the integral equations. Using the notation of equations (19) and (20) we can write the triple integral equations (1) and (2) as

$$
\begin{gathered}
\mathfrak{M}^{-1}\left\{\frac{\Gamma(\xi+s / \delta)}{\Gamma(\xi+\beta+s / \delta)} \Phi(s) ; x\right\}=g(x), \\
\mathfrak{M}^{-1}\left\{\frac{\Gamma(1+\eta-s / \sigma)}{\Gamma(1+\eta+\alpha-s / \sigma)} \Phi(s) ; x\right\}=f(x),
\end{gathered}
$$

where $g_{1}=g_{3}=0, f_{2}$ is given and $g_{2}, f_{1}$ and $f_{3}$ are unknown functions.

If we write

$$
\Phi(s)=\mathfrak{M}\{\dot{\phi}(x) ; s\},
$$

and use the formulae (16) and (17) we find that equations (25) and (26) assume the operational form

$$
\begin{gathered}
I_{\eta, \alpha}(0, x: \sigma) \phi(x)=f(x), \\
K_{\xi, \beta}(x, \infty: \delta) \phi(x)=g(x) .
\end{gathered}
$$

Using the formulae (8) and (9) and solving the above equations for $\phi(x)$ we obtain

$$
\begin{aligned}
\phi(x) & =I_{\eta+\alpha,-\alpha}(0, x: \sigma) f(x) \\
& =K_{\xi+\beta,-\beta}(x, \infty: \delta) g(x) .
\end{aligned}
$$

Now remembering that $g_{1}=g_{3}=0$, and using the relations (22), (23) and (24) to evaluate equation (28) on the interval $I_{1}$, equation (30) on $I_{2}$, equation (31) on $I_{3}$, equation (29) on $I_{2}$ and equation (31) on $I_{1}$, we arrive at the following results

$$
\begin{gathered}
f_{1}(x)=I_{\eta, \alpha}(0, x: \sigma) \phi_{1}(x), \\
\phi_{2}(x)=I_{\eta+\alpha,-\alpha}(0, a: \sigma) f_{1}(x)+I_{\eta, \alpha}^{-1}(a, x: \sigma) f_{2}(x), \\
\phi_{3}(x)=K_{\xi, \beta}^{-1}(x, \infty: \delta) g_{3}(x)=0, \\
g_{2}(x)=K_{\xi, \beta}(x, b: \delta) \phi_{2}(x), \\
\phi_{1}(x)=K_{\xi+\beta,-\beta}(a, b: \delta) g_{2}(x) .
\end{gathered}
$$

After eliminating $f_{1}(x)$ between equations (32) and (33), and eliminating $g_{2}(x)$ between equations (35) and (36), we find that the functions $\phi_{1}(x)$ and $\phi_{2}(x)$ satisfy the pair of simultaneous integral equations

$$
\begin{gathered}
\dot{\phi}_{2}(x)=-L_{\eta, \alpha}(0, x: \sigma) \phi_{1}(x)+I_{\eta, \alpha}^{-1}(a, x: \sigma) f_{2}(x), \\
\phi_{1}(x)=-M_{\xi, \beta}(x, b: \delta) \phi_{2}(x),
\end{gathered}
$$


where we have used the formulae (14) and (15).

From these results it is easily seen that $\phi_{2}(x)$ can be determined from the Fredholm integral equation of the second kind

$$
\phi_{2}(x)=L_{\eta, \alpha}(0, x: \sigma) M_{\xi, \beta}(x, b: \delta) \phi_{2}(x)+I_{\eta, \alpha}^{-1}(a, x: \sigma) f_{2}(x) .
$$

The solution to the triple integral equations can then be obtained from equations (27), (34), (38) and (39).

As an example we consider the case when $0<\alpha<1$, and $-1<\beta<0$, or $0<\beta<1$; in this instance equation (39) when written out in detail is

$$
\begin{aligned}
\phi_{2}(x) & -\int_{a}^{b} \phi_{2}(u) S(x, u) d u \\
= & \frac{x^{1-\sigma(\eta+1)}}{\Gamma(1-\alpha)} \frac{d}{d x} \int_{a}^{x} \frac{t^{\sigma(\alpha+\eta+1)-1}}{\left(x^{\sigma}-t^{\sigma}\right)^{\alpha}} f_{2}(t) d t,
\end{aligned}
$$

where

$$
\begin{aligned}
S(x, u)= & \frac{\sigma \delta}{\pi^{2}} \sin (\alpha \pi) \sin (\beta \pi) \frac{x^{-\sigma \eta} u^{\delta(1-\beta-\xi)-1}}{\left(x^{\sigma}-a^{\sigma}\right)^{\alpha}\left(u^{\hat{\delta}}-a^{\delta}\right)^{-\beta}} \\
& \int_{0}^{a} \frac{t^{\sigma(\eta+1)+\delta(\beta+\xi)-1}\left(a^{\sigma}-t^{\sigma}\right)^{\alpha}}{\left(x^{\sigma}-t^{\sigma}\right)\left(u^{\delta}-t^{\delta}\right)\left(a^{\delta}-t^{\delta}\right)^{\beta}} d t .
\end{aligned}
$$

4. An application. Certain mixed boundary value problems [4] may be reduced to the solution of triple integral equations of the type

$$
\begin{array}{ll}
\int_{0}^{\infty} \psi(u) J_{2 p}(u x) d u=0, \quad 0 \leqq x<a, & b<x<\infty, \\
\int_{0}^{\infty} u^{-2 n} \psi(u) J_{2 q}(u x) d u=F(x), & a<x<b,
\end{array}
$$

where $J_{2 p}(u x)$ is the Bessel function of the first kind of order $2 p, F(x)$ is a prescribed function and $\psi(u)$ is to be determined. When $p=q$ these are the equations investigated by Cooke [1]. We now show, in a fairly straightforward manner, that the above equations can be transformed into equations of the type (1) and (2).

Denoting the Mellin transform of $\psi(u)$ by

$$
\mathfrak{M}\{\psi(u) ; s\}=\Psi(s),
$$

and using the result [3]

$$
\mathfrak{M}\left\{\xi^{-2 n} J_{2 q}(\xi) ; s\right\}=2^{s-1-2 n} \frac{\Gamma(q-n+s / 2)}{\Gamma(1+n+q-s / 2)},
$$

we have, on applying the Faltung theorem for Mellin transforms [3], 
that the integral equations (42) and (43) can be written in the form

$$
\begin{aligned}
& \mathfrak{M}^{-1}\left\{\frac{\Gamma(p+s / 2)}{\Gamma(q-n+s / 2)} \Phi(s) ; x\right\}=0, \quad 0 \leqq x<a, \quad b<x<\infty, \\
& \mathfrak{M}^{-1}\left\{\frac{\Gamma(1+p-s / 2)}{\Gamma(1+n+q-s / 2)} \Phi(s) ; x\right\}=2^{1+2 n} x^{-2 n} F(x), \quad a<x<b,
\end{aligned}
$$

where

$$
\Phi(s)=2^{s} \frac{\Gamma(q-n+s / 2)}{\Gamma(1+p-s / 2)} \Psi(1-s) .
$$

These are the same as equations (1) and (2) with

$$
\begin{aligned}
\sigma & =\delta=2, \xi=\eta=p, \alpha=q-p+n, \beta=q-p-n, \\
f_{2}(x) & =2^{1+2 n} x^{-2 n} F(x) .
\end{aligned}
$$

Using the results of the previous section we have therefore that the solution of equations (46) and (47) can be found in terms of a function $\phi(x)$ by

$$
\Phi(s)=\mathfrak{M}\{\phi(x) ; s\},
$$

where $\phi_{3}(x)=0$ and the functions $\phi_{1}(x)$ and $\phi_{2}(x)$ are obtained from equations (38) and (39) with the parameters $\xi, \eta$, etc. given by equations (49).

Finally, in order to find the solution of the integral equations (42) and (43) in terms of $\phi(x)$, we proceed in the following way.

From equation (44) we have that the solution is

$$
\begin{aligned}
\psi(u) & =\mathfrak{M}^{-1}\{\Psi(s) ; u\} \\
& =\mathfrak{M}^{-1}\left\{2^{s-1} \frac{\Gamma(1 / 2+p+s / 2)}{\Gamma(1 / 2+q-n-s / 2)} \mathfrak{M}\{\phi(x) ; 1-s\} ; u\right\},
\end{aligned}
$$

on using equations (48) and (50). Inverting the order of integration in the last equation we get

$$
\begin{aligned}
\psi(u) & =\int_{0}^{\infty} \phi(x) \mathfrak{M}^{-1}\left\{2^{s-1} \frac{\Gamma(1 / 2+p+s / 2)}{\Gamma(1 / 2+q-n-s / 2)} ; u x\right\} d x \\
& =\int_{0}^{\infty}\left(\frac{u x}{2}\right)^{1+n+p-q} \phi(x) J_{p+q-n}(u x) d x,
\end{aligned}
$$

after applying the result (45). When $p=q$ this solution is exactly the same as that found by Cooke [1, pp. 61-62]. 


\section{REFERENCES}

1. J. C. Cooke, The solution of triple integral equations in operational form, Quart. J. Mech. Appl. Math., 18 (1965), 57-72.

2. A. Erdelyi, Some dual integral equations, SIAM J. Appl. Math., 16 (1968), 1338-1340.

3. I. N. Sneddon, Functional Analysis, Handbuch der Physik, Vol. 2, Springer-Verlag, Berlin, 1955.

4. — Mixed boundary value problems in potential theory, North-Holland, 1966. 5. R. P. Srivastav and K. S. Parihar, Dual and triple integral equations involving inverse Mellin transforms, SIAM J. Appl. Math., 16 (1968), 126-133.

Received May 26, 1970.

UNIVERSITY OF STRATHCLYDE

GLASGOW, SCOTLAND 



\section{PACIFIC JOURNAL OF MATHEMATICS}

\section{EDITORS}

\author{
H. SAMELSON \\ Stanford University \\ Stanford, California 94305 \\ C. R. HовBY \\ University of Washington \\ Seattle, Washington 98105
}

J. DUGUndis

Department of Mathematics

University of Southern California

Los Angeles, California 90007

RICHARD ARENS

University of California

Los Angeles, California 90024

\section{ASSOCIATE EDITORS}
E. F. BeCKenbaCH
B. H. NeUmanN
F. WOLF
K. YoshidA

\section{SUPPORTING INSTITUTIONS}

\author{
UNIVERSITY OF BRITISH COLUMBIA \\ CALIFORNIA INSTITUTE OF TECHNOLOGY \\ UNIVERSITY OF CALIFORNIA \\ MONTANA STATE UNIVERSITY \\ UNIVERSITY OF NEVADA \\ NEW MEXICO STATE UNIVERSITY \\ OREGON STATE UNIVERSITY \\ UNIVERSITY OF OREGON \\ OSAKA UNIVERSITY \\ UNIVERSITY OF SOUTHERN CALIFORNIA
}

\author{
STANFORD UNIVERSITY \\ UNIVERSITY OF TOKYO \\ UNIVERSITY OF UTAH \\ WASHINGTON STATE UNIVERSITY \\ UNIVERSITY OF WASHINGTON

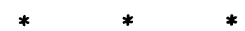 \\ AMERICAN MATHEMATICAL SOCIETY \\ CHEVRON RESEARCH CORPORATION \\ NAVAL WEAPONS CENTER
}

The Supporting Institutions listed above contribute to the cost of publication of this Journal, but they are not owners or publishers and have no responsibility for its content or policies.

Mathematical papers intended for publication in the Pacific Journal of Mathematics should be in typed form or offset-reproduced, (not dittoed), double spaced with large margins. Underline Greek letters in red, German in green, and script in blue. The first paragraph or two must be capable of being used separately as a synopsis of the entire paper. The editorial "we" must not be used in the synopsis, and items of the bibliography should not be cited there unless absolutely necessary, in which case they must be identified by author and Journal, rather than by item number. Manuscripts, in duplicate if possible, may be sent to any one of the four editors. Please classify according to the scheme of Math. Rev. Index to Vol. 39. All other communications to the editors should be addressed to the managing editor, Richard Arens, University of California, Los Angeles, California, 90024.

50 reprints are provided free for each article; additional copies may be obtained at cost in multiples of 50 .

The Pacific Journal of Mathematics is published monthly. Effective with Volume 16 the price per volume (3 numbers) is $\$ 8.00$; single issues, $\$ 3.00$. Special price for current issues to individual faculty members of supporting institutions and to individual members of the American Mathematical Society: $\$ 4.00$ per volume; single issues $\$ 1.50$. Back numbers are available.

Subscriptions, orders for back numbers, and changes of address should be sent to Pacific Journal of Mathematics, 103 Highland Boulevard, Berkeley, California, 94708.

PUBLISHED BY PACIFIC JOURNAL OF MATHEMATICS, A NON-PROFIT CORPORATION

Printed at Kokusai Bunken Insatsusha (International Academic Printing Co., Ltd.), 7-17, Fujimi 2-chome, Chiyoda-ku, Tokyo, Japan. 


\section{Pacific Journal of Mathematics}

Vol. 38, No. $2 \quad$ April, 1971

Richard Davis Anderson and Thomas Ashland Chapman, Extending

homeomorphisms to Hilbert cube manifolds .................. 281

Nguyen Huu Anh, Restriction of the principal series of $\operatorname{SL}(n, \mathbf{C})$ to some

reductive subgroups................................ 295

David W. Boyd, Indices for the Orlicz spaces . . . . . . . . . . . . 315

William Garfield Bridges, The polynomial of a non-regular digraph ...... 325

Billie Chandler Carlson, Robert K. Meany and Stuart Alan Nelson, Mixed

arithmetic and geometric means........................ 343

H. A. Çelik, Commutative associative rings and anti-flexible rings ...... 351

Hsin Chu, On the structure of almost periodic transformation groups ...... 359

David Allyn Drake, The translation groups of n-uniform translation

Hjelmslev planes ................................ 365

Michael Benton Freeman, The polynomial hull of a thin two-manifold . . . . 377

Anthony Alfred Gioia and Donald Goldsmith, Convolutions of arithmetic

functions over cohesive basic sequences .................... 391

Leslie C. Glaser, A proof of the most general polyhedral Schoenflies

conjecture possible ................................

Thomas Lee Hayden and Ted Joe Suffridge, Biholomorphic maps in Hilbert

space have a fixed point ................................ 419

Roger Alan Horn, Schlicht mappings and infinitely divisible kernels ...... 423

Norman Ray Howes, On completeness ...................... 431

Hideo Imai, Sario potentials on Riemannian spaces................ 441

A. A. Iskander, Subalgebra systems of powers of partial universal

algebras.

Barry E. Johnson, Norms of derivations of $\mathscr{L}(\mathrm{X})$.

David Clifford Kay and Eugene W. Womble, Axiomatic convexity theory and relationships between the Carathéodory, Helly, and Radon numbers

Constantine G. Lascarides, A study of certain sequence spaces of Maddox

and a generalization of a theorem of Iyer .............

C. N. Linden, On Blaschke products of restricted growth .

John S. Lowndes, Some triple integral equations ................. 515

Declan McCartan, Bicontinuous preordered topological spaces ......... 523

S. Moedomo and J. Jerry Uhl, Jr., Radon-Nikodým theorems for the Bochner and Pettis integrals ...

Calvin Cooper Moore and Joseph Albert Wolf, Totally real representations

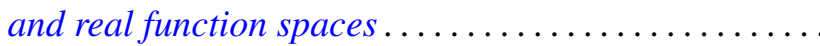

Reese Trego Prosser, A form of the moment problem for Lie groups. ... 